\title{
Comparison of Nannochloropsis sp. cells disruption between hydrodynamic cavitation and conventional extraction
}

\author{
Martomo Setyawan ${ }^{1,2}$, Panut Mulyono ${ }^{1}$, Sutijan ${ }^{1}$, and Arief Budiman ${ }^{1,3, *}$ \\ ${ }^{1}$ Chemical Engineering Department, Gadjah Mada University, Jalan Grafika 2 Yogyakarta, Indonesia \\ ${ }^{2}$ Faculty of Industrial Engineering, Ahmad Dahlan University, Jalan Prof DR Soepomo SH Yogyakarta, Indonesia \\ ${ }^{3}$ Center for Energy Studies, Gadjah Mada University, Sekip K IA, Yogyakarta, Indonesia
}

\begin{abstract}
Biodiesel production from microalgae is one of the solution of the future energy problem, but its production cost is still high. One of the costly stages of this process is the lipid extraction process. It can be reduced by microalgae cell disruption. One of the mechanical method to cell disruption with the lowest energy requirement is hydrodynamic cavitation. This aim of this study is to evaluate the distribution coefficient and the mass transfer coefficient value of lipid extraction of Nannochloropsis $s p$. assisted by hydrodynamic cavitation and compare with conventional extraction. The hydrodynamic cavitation extraction was done at 34 ${ }^{\circ} \mathrm{C}, 1 \mathrm{~atm}$. The conventional extraction was done at $34{ }^{\circ} \mathrm{C}, 1 \mathrm{~atm}$ with stirring speed 260 and $1000 \mathrm{rpm}$. The experimental result shows that the distribution coefficient dependent on the temperature with the values for $50,44,38$ and $34{ }^{\circ} \mathrm{C}$ were $0.502,0.394,0.349$, and 0.314 respectively. And it was according to Van' Hoff equation with the values of $\Delta \mathrm{H}^{\circ}$ was $20.718 \mathrm{~kJ} / \mathrm{mol}$ and $\Delta \mathrm{S}^{\circ}$ was $58.05 \mathrm{~J} / \mathrm{mol} / \mathrm{K}$. The hydrodynamic cavitation extraction was faster than conventional. The mass transfer coefficient values for hydrodynamic cavitation, conventional $260 \mathrm{rpm}$ and $1000 \mathrm{rpm}$ were $7.373,0.534$ and $0.1211 / \mathrm{s}$ respectively.
\end{abstract}

\section{Introduction}

The increasing energy demand in the recent years and the decreasing fossil fuel stock will induce the energy problem related to the supply of raw material [1]. One of the solutions is to find the alternative renewable energy sources. Some renewable energy sources have been investigated by some researchers. The large stock of renewable energy source that already exists is palm oil to make biodiesel, but producing biodiesel from palm oil will make a threat to the food security [2]. Non-edible energy sources have been investigated to develop the second generation of biodiesel. These sources were like palm fatty acid distillate [3], oil palm empty fruit bunches (EFB)[4], wood waste [5], and non-edible seeds such as Jatropha seed [6]. However these non-edible energy sources are limited inventory. At the last recent time, some researchers give their attention to make the third generation of biodiesel from microalgae lipids [7].

Microalgae have been proved as a candidate for fuel production (algae fuel) with several benefits. The benefits of microalgae are their higher photosynthetic efficiency, higher biomass production, and faster growth than to the other energy crops [8]. Microalgae can be cultivated in large scale on non-arable lands and do not need potable water to grow. So, there is not threatening to the food production [9]. The important problem associated with using fuel is the increasing carbon dioxide emission as a pollutant that causes global warming. Another benefit from microalgae is to prevent global warming caused by carbon dioxide emission into the air, since microalgae need carbon dioxide to grow. Carbon dioxide as a burning product can be absorbed by microalgae are used for photosynthesis to product lipids [10].

The processes to produce biodiesel from microalgae involve cultivation, harvesting, lipid extraction and transesterification. Intensive research in this field over several years are still hindered by high overall production costs. It makes uncompetitive in the market. So, finding the processes with low production costs become preponderant [11]. Among of these steps of processes, the lipid extraction process is the most costly process with the portion of $70-80 \%$ of total cost [12]. Lipid extractions were reported in some literatures $[9,10,11]$. It was starting from conventional to the advanced methods of extraction. The conventional extraction just using chemical solvent and stirring, this process has low efficiency and need a long time of extraction [13]. The advanced methods of extraction were done by assisted cell disruption, this processes got higher efficiency than the conventional extraction. So mechanical treatment, such as mechanical disruption is needed to ensure the complete extraction of lipids.

\footnotetext{
* Corresponding author: abudiman@ugm.ac.id
} 
Lipid extractions assisted by mechanical cell disruption have been published. Autoclaving, beadbeating, high-pressure homogenization, and ultrasonification were commonly practiced methods $[14,15,16]$. The hydrodynamic cavitation is one of the mechanical cell disruptions that needs the smallest amount of energy [17]. Hydrodynamic cavitation that was used to cell disruption technique was investigated, with the level of cell disruption was determined by lipids extracted and chlorophyll released. It was found that for lipids extraction, hydrodynamic cavitation technique was requiring energy as big as $3 \mathrm{MJ} / \mathrm{kg}$ with the microalgae concentration $1.5-2 \%$ w/w [18]. Hydrodynamic cavitation to assist lipid extraction simultaneously from Nannochloropsis Salina $s p$. was reported with variables of amount of energy input, time of extraction as compared to ultrasonic cavitation. This hydrodynamic cavitation was resulting in higher extraction yield at the same energy input with the microalgae concentration was used $2 \% \mathrm{w} / \mathrm{vol}$ [19].

However to scale up lipid extraction assisted by hydrodynamic cavitation need the value of mass transfer coefficient. The aim of this study is to investigate the value of mass transfer coefficient. To evaluate this coefficient, the mathematical models are proposed and the experimental data are used to verify the model. The mathematical models are including equilibrium and mass balance models.

\section{Materials and Methods}

\subsection{Materials}

Dry microalgae Nannochloropsis sp.was purchased from Balai Budidaya Air Payau in Situbondo East Java Indonesia. N-Hexane technical grade (Density of nhexane $=0.66 \mathrm{~kg} / \mathrm{cc}$ and normal boiling point $=68^{\circ} \mathrm{C}$ ) was purchased from PT. Brataco Chemica, a local chemical store in Yogyakarta Indonesia. Methanol technical grade (Density of methanol $=0.791 \mathrm{~kg} / \mathrm{cc}$, molecule weight of methanol $=32.034 \mathrm{~g} / \mathrm{mol}$ and normal boiling point $=64.7^{\circ} \mathrm{C}$ ) was purchased from CV. Multi Kimia, a local chemical store in Yogyakarta Indonesia.

\subsection{Equipment}

Equilibrium experiment for conventional extraction was carried out in the $150 \mathrm{ml}$ erlenmeyer and the magnetic stirrer with heater. To ensure there was no solvent vaporization this Erlenmeyer was equipped with the condenser pipe. The experiments of hydrodynamic cavitation were carried out on batch extraction cavitation (Figure 1). The equipments were configured of a compressor to provide the driving compressed air to drive the mixture of solvent and microalga. Venturi was used to generate cavitation. Sample and product chamber were to place the sample and collect raw product respectively. The separation equipment were thickener and evaporator, thickener was used to separate the fluid and solid product by gravitational force, and the evaporator was used to evaporate the solvent, and lipid can be found as a residue.

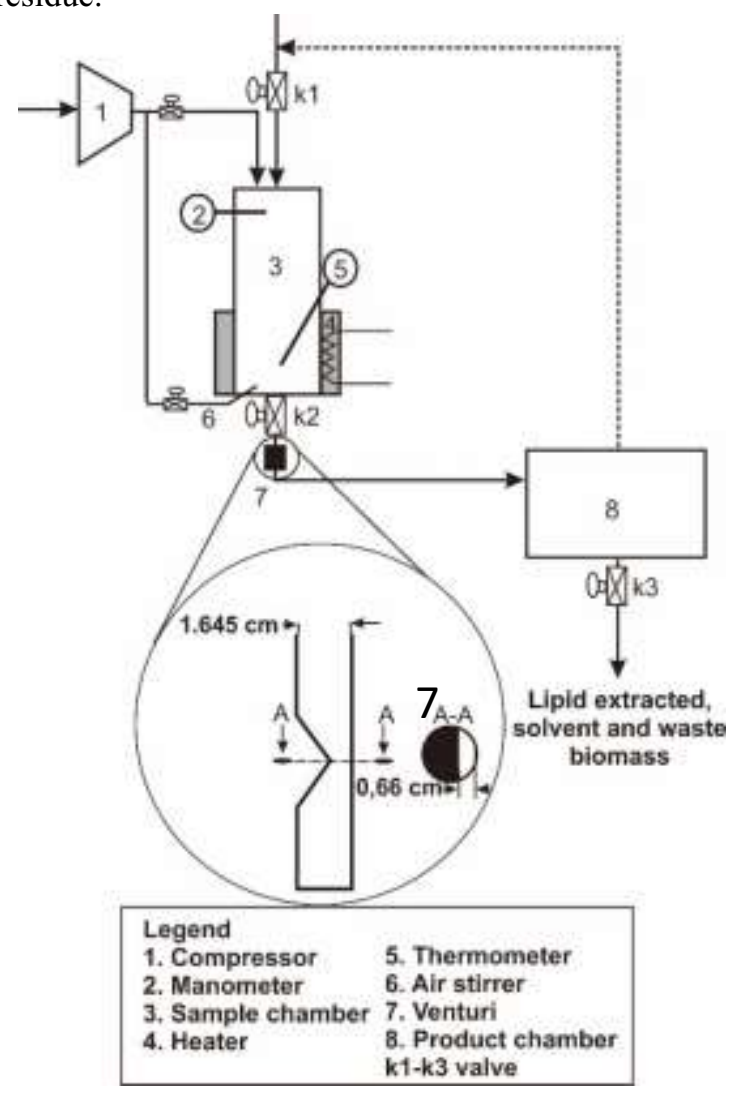

Fig 1. The scheme of hydrodynamic cavitation equipment

\subsection{Experimental Procedures}

The equilibrium experiments were done by mixing dry Nannochloropsis $s p$. with the mixture solvent methanol and hexane with the various ratios at the erlenmeyer. The mixture then was mixed for 8 hours at the $300 \mathrm{rpm}$ mixing and then solid and fluid should be separated using a centrifuge. To determine lipids concentration in the fluid phase, measured liquid volume and weight, and lipids content in the fluid phase were determined by gravimeter after all the solvent were evaporated.

The hydrodynamic cavitation extraction experiments were done with 10 grams dry weight of Nannochloropsis sp. and solvent consists of $95 \mathrm{ml}$ of hexane and $41 \mathrm{ml}$ of methanol. All of the material were inputted into the sample chamber and then were flowed through the venturi with the pressure sample chamber $6.8 \mathrm{~atm}$. Repeat this procedure for several rounds $(2,3$, 4 , etc.) as variable extraction. After the extraction processes have been finished, the fluid and solid phase were separated by sedimentation process. The remaining solids were washed with $25 \mathrm{ml}$ of methanol and $25 \mathrm{ml}$ of hexane separately. Washing methanol and hexane were combined with solvents that have been separated in the first step. The next step was separating lipid and solvent by distillation to obtain a residue with a constant weight. The residue was weighed and recorded as $\mathrm{w}_{1}$. It was washed with hexane $5 \mathrm{ml}$ and 
the remaining solids were dried until the weight remains constant and recorded as $\mathrm{w}_{2}$ and lipid weight $\left(\mathrm{w}_{\mathrm{p}}\right)$ obtained from microalgae was calculated using

$$
\mathrm{w}_{\mathrm{p}}=\mathrm{w}_{1}-\mathrm{w}_{2}
$$

Extraction yield is the weight of extracted lipids which is compared with the weight of dry microalgae in the beginning.

$$
y=\frac{w_{p}}{w_{m i}}
$$

where y is extraction yield, $w_{m i}$ is weight of dry microalgae at the beginning.

\subsection{Mathematical model}

In the solid-fluid extraction at the initial condition concentration lipids in the solvent (y) is zero, the changing value of $y$ as function of the time is equal with the number lipids release from the solid $\left(\mathrm{j}_{\mathrm{T}}\right)$, so it can be written as the equation (3)

$$
m_{f} \frac{\partial y}{d t}=j_{T}
$$

where $m_{f}$ represents the mass of fluid phase, $t$ represents time. Lipids concentration in the solid can be calculated by lipids mass balance in the solid that can be written as

$$
m_{s} \frac{d x}{d t}=-j_{T}
$$

where $m_{s}$ represent the dry microalgae mass. The amount lipids release are equal with the mass transfer coefficient multiply with the concentration gradient between microalgae surface and in the bulk of liquid, and it can be written as

$$
j_{T}=k_{T} a_{T} \rho_{f}\left(y^{*}-y\right)
$$

where $k_{T} a_{T}$ represent volumetric mass transfer coefficient, $\rho_{f}$ represent fluid density, and $y^{*}$ represent lipids concentration at the microalgae surface. Value of $y^{*}$ can be predicted by equations

$$
y^{*}=K \cdot x
$$

where $\mathrm{K}$ represents distribution coefficient, $\mathrm{x}$ represents lipid concentration in the solid phase. The value of $\mathrm{K}$ can be calculated from data of equilibrium experiment with the equation (7).

$$
K=\frac{C_{\infty}}{C_{s}}
$$

where $\mathrm{C}_{\infty}$ is the lipid concentration in the solvent ( $\mathrm{g}$ oil/ solvent volume) and $\mathrm{C}_{\mathrm{s}}$ is the lipid concentration in the solid phase (g oil/g dry microalga). The value of $\mathrm{C}_{\infty}$ was taken from experiment and $\mathrm{C}_{\mathrm{s}}$ was calculated from initial concentration reduced by lipid released divided by the weight of dry microalgae.
The thermodynamic parameter of enthalpy change $\Delta H^{o}(\mathrm{~kJ} / \mathrm{mol})$ and entropy change $\Delta S^{o}(\mathrm{~J} / \mathrm{mol} / \mathrm{K})$ are evaluated by Van't Hoff equation [20]:

$$
\ln K=-\frac{\Delta H^{o}}{R T}+\frac{\Delta S^{o}}{R}
$$

where $R$ is the universal gas constant $(\mathrm{J} / \mathrm{mol} / \mathrm{K})$. The other parameter Gibbs free energy change $\Delta G(\mathrm{~kJ} / \mathrm{mol})$ is determined by equation

$$
\Delta G=\Delta H^{o}-T \Delta S^{o}
$$

Model evaluation was done by calculating determination coefficient $\left(\mathrm{R}^{2}\right)$.

\section{Results and discussions}

The dry Nannochloropsis $s p$. microalgae was determined the total lipid content using stirring extraction method. 5 grams of dry Nannochloropsis sp. was extracted using $47.5 \mathrm{ml}$ hexane and $20.5 \mathrm{ml}$ methanol then stirred at speed of stirring $1100 \mathrm{rpm}$ for 2 hours operation every stage. This extraction processes were done 3 stages at the room temperature $\left(34{ }^{\circ} \mathrm{C}\right)$. The total lipid content of dry Nannochloropsis $s p$. that was used as the sample was $10.46 \%$ gram lipids/gram of dry Nannochloropsis sp. microalgae. The lipids composition were determined by Gas Chromatography-mass spectrometry. And the lipids were composed of fatty acids with $\mathrm{C} 20$ and $\mathrm{C} 17$ atoms chain with a composition of $69.81 \%$ and $14.63 \%$ respectively. The content of fatty acids in these lipids indicate that lipids from microalgae Nannochloropsis $s p$. potentially to be processed into biodiesel.

\subsection{Equilibrium experiment}

The yield of extraction lipid from 5 grams dry Nannochloropsis sp. using mixer solvents hexane (23 $\mathrm{ml})$ and methanol $(10 \mathrm{ml})$ as function of time extraction. The extraction processes was done by conventional methods with stirring speed $300 \mathrm{rpm}$ at the room temperature $\left(32{ }^{\circ} \mathrm{C}\right)$. For extraction time under 8 hours the extraction processes have not reached equilibrium state because there is increasing yields. At this case for 5 hours extraction time the yield is $5.25 \%$ and for 8 hours the yield is $6.76 \%$ and then after 8 hours the yield relatively constant. It is mean after 8 hours the extraction processes have reached the equilibrium state.

Figure 2 shows the various relationship between concentration lipids in the solids phase (x) and the fluid phase (y) at the equilibrium state. The variation of concentration was setting by different number of ratio dry microalgae and the mixture solvent, but the solvent volume ratio between hexane and methanol was fixed 2.3:1. The experiments were done at the temperatures 34, 38, 44 and $50{ }^{\circ} \mathrm{C}$. From Figure 2 shown that the temperature took effect to the distribution coefficient (K) value. To determine the $\mathrm{K}$ value, it was approached by linier regression for each temperature data group. 
The linier regression results and the determine coefficients $\left(\mathrm{R}^{2}\right)$ and distribution coefficients values are listed in the Table 1.

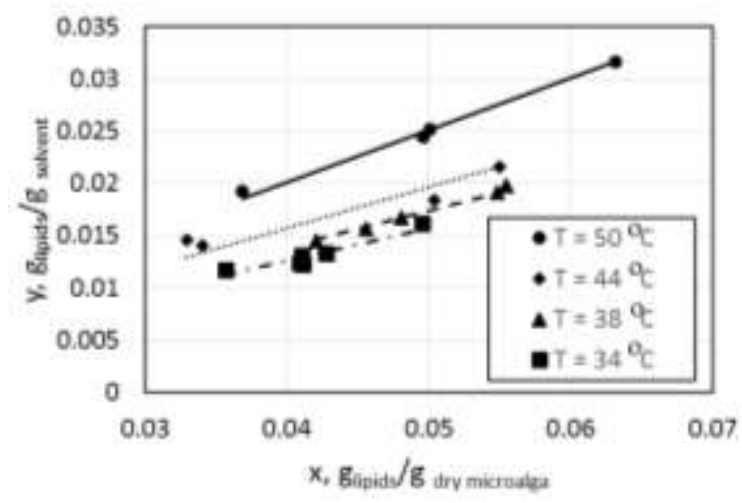

Fig 2. Variation ratio lipids concentration in the solid (x) and in the fluid (y) at different temperature

\subsection{Enthalpy change, entropy change and Gibbs free energy change}

Table 1 shows $\mathrm{K}$ values for different temperatures, the highest temperature in this experiment give the largest $\mathrm{K}$ value, and decreasing temperatures tend to decrease $\mathrm{K}$ values. The relation of $\mathrm{K}$ as function of the temperature is approaching by Van't Hoff equation (Equation (6)), using this equation the enthalpy change and entropy change can be predicted. The approaching results using Van't Hoff equation are shown in the Figure 3.

Table 1. Values of distribution coefficient, enthalpy change and entropy change

\begin{tabular}{|c|c|c|c|c|}
\hline $\mathrm{T},{ }^{\circ} \mathrm{C}$ & $\mathrm{K}$ & $\mathrm{R}^{2}$ & $\begin{array}{c}\Delta \mathrm{H}^{\circ}, \\
\mathrm{J} / \mathrm{mol}\end{array}$ & $\begin{array}{c}\Delta \mathrm{S}^{\circ}, \\
\mathrm{J} / \mathrm{mol} / \mathrm{K}\end{array}$ \\
\hline 50 & 0.502 & 0.990 & & \\
\cline { 1 - 3 } 24 & 0.394 & 0.858 & 20718.5 & 5 \\
\cline { 1 - 3 } 38 & 0.349 & 0.987 & 9 & 5.05099 \\
\cline { 1 - 2 } 32 & 0.314 & 0.891 & & \\
\hline
\end{tabular}

Figure 3 shows plotting data and approaching line $\mathrm{K}$ value as function of temperatures. The approaching line is well represent the data with the $\mathrm{R}^{2}$ value is 0.946 , with the enthalpy change and entropy change value are $20718.59 \mathrm{~J} / \mathrm{mol}$ and $58.05 \mathrm{~J} / \mathrm{mol} / \mathrm{K}$. The value of Gibbs free energy change as function of temperatures are calculated using equation (9). Values of Gibbs free energy for various temperatures are listed in the Table 2.

Enthalpy change $\left(\Delta \mathrm{H}^{\circ}\right)$ value is $20.72 \mathrm{~kJ} / \mathrm{mol}$ it is mean that the extraction lipid from Nannochloropsis $s p$. is endothermic process. The $\Delta \mathrm{H}^{\circ}$ of this process is larger than the range of $\Delta \mathrm{H}^{\circ}$ of oil extraction process that was agreement between $4-13.5 \mathrm{~kJ} / \mathrm{mol}$ [21]. It is mean that to extract lipid from Nannochloropsis sp. need more energy than another oil plant sources. The positive value of $\Delta \mathrm{S}^{\circ}$ is indicating this process is irreversible.

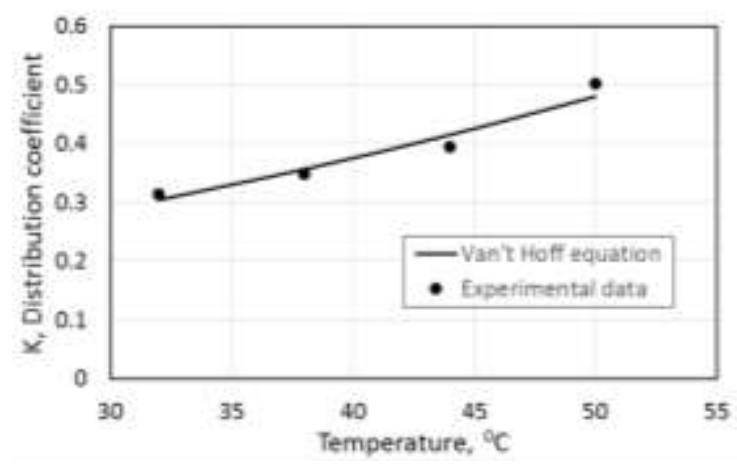

Fig 3. K values as function temperatures and the approaching line

Table 2. Values of Gibbs free energy change for some temperatures

\begin{tabular}{|c|c|c|}
\hline $\mathrm{T},{ }^{\circ} \mathrm{C}$ & $\Delta \mathrm{G}, \mathrm{J} / \mathrm{mol}$ & \multirow{2}{*}{$\mathrm{R}^{2}$} \\
\hline 50 & 1969.312 & \multirow{2}{*}{0.946} \\
\hline 44 & 2317.355 & \\
\hline 38 & 2665.399 & \\
\hline 32 & 3013.442 & \\
\hline
\end{tabular}

The value of Gibbs free energy for temperature $50{ }^{\circ} \mathrm{C}$ and below are positive, this is indicated that the extraction lipid from Nannochloropsis sp.for this temperature range is not spontaneous. Based on the thermodynamic evaluation, the lipid extraction from Nannochloropsis sp. need more energy than another oil-plant sources. This energy is used to cell disruption.

\subsection{Comparison of hydrodynamic cavitation and conventional lipid extraction}

Figure 4 shows comparison phenomena of lipid extraction as function of extraction time among hydrodynamic cavitation with pressure booster 6.8 atm, conventional with $260 \mathrm{rpm}$ stirring speed and conventional with $1000 \mathrm{rpm}$ stirring speed. All of the experiment were done at the $34{ }^{\circ} \mathrm{C}$ and pressure $1 \mathrm{~atm}$. The amount of dry Nannochloropsis sp., hexane and methanol for all experiment were constant. The weight of dry Nannochloropsis sp. was 5 grams, volume of hexane was $47.5 \mathrm{ml}$ and volume methanol was $20.5 \mathrm{ml}$.

From Figure 4, we may see that the phenomena of lipid extraction assisted by hydrodynamic cavitation is the fastest methods as compared to the conventional methods with stirring speed 260 and $1000 \mathrm{rpm}$. The time to get $8.9 \%$ yield by hydrodynamic cavitation extraction need time less than 10 minutes, while using conventional methods for extraction time 60 minutes the yields $7.3 \%$ for $1000 \mathrm{rpm}$ stirring speed and $5.44 \%$ for $260 \mathrm{rpm}$ stirring speed. This comparison is indicate that extraction process assisted by hydrodynamic cavitation is very effective methods. And if it is compared to another cell disruption methods the hydrodynamic cavitation is most effective [19]. 


\subsection{Volumetric mass transfer coefficient}

Volumetric mass transfer coefficient of Nannochloropsis sp. lipid extraction was evaluated using equations (3), (4), (5) and (6). The experimental data of equilibrium were used to calculate $\mathrm{K}$ by equation (7). Equations (3) and (4) were solved using Runge Kutta Method and the value of volumetric mass transfer coefficient was evaluated using one variable minimization Golden Section Method. The model calculation results represent in the Figure 4. It shows phenomena of lipid extraction from Nannochloropsis $s p$. using three different methods there were hydrodynamic cavitation (HC), extraction with 260 $\mathrm{rpm}$ stirring speed and $1000 \mathrm{rpm}$ stirring speed. The value of volumetric mass transfer coefficient of three different methods are listed in the Table 3.

Table 3. Volumetric mass transfer coefficient of three different methods

\begin{tabular}{|c|c|c|}
\hline \multicolumn{3}{|c|}{$k_{T} a_{T}, 1 / \mathrm{s}$} \\
\hline HC & $\begin{array}{c}1000 \mathrm{rpm} \\
\text { stirring }\end{array}$ & $\begin{array}{c}260 \mathrm{rpm} \\
\text { stirring }\end{array}$ \\
\hline 7.375 & 0.534 & 0.121 \\
\hline
\end{tabular}

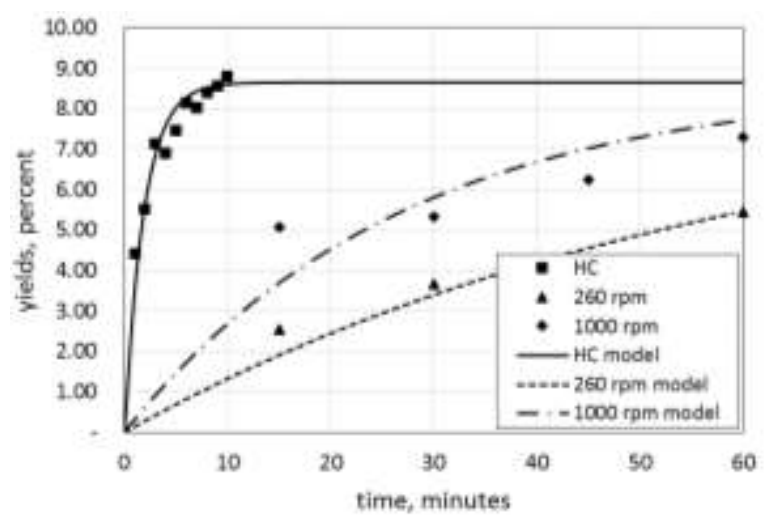

Fig 4. Experimental and simulated model of three different methods

\section{Conclusions}

The distribution coefficient of lipid extraction process of Nannochloropsis sp. using methanol and hexane solvents are affected by temperature with the values for temperatures $34,38,44$ and $50{ }^{\circ} \mathrm{C}$ are $0.314,0.349$, 0.394 and 0.502 , respectively. The value of thermodynamic parameter $\Delta \mathrm{H}^{\circ}$ and $\Delta \mathrm{S}^{\circ}$ are 20.72 $\mathrm{kJ} / \mathrm{mol}$ and $58.05 \mathrm{~J} / \mathrm{mol} / \mathrm{K}$ respectively. The Gibbs free energy values are affected by temperatures. These values for temperatures $34,38,44$ and $50{ }^{\circ} \mathrm{C}$ are 3.013 , 2.665, 2.317 and $1.969 \mathrm{~kJ} / \mathrm{mol}$ respectively. Based on the thermodynamic parameter values lipid extraction of Nannochloropsis $s p$. process is endothermic, irreversible and not spontaneous.

Lipid extraction by hydrodynamic cavitation is the fastest process as compared to the conventional methods. The volumetric mass transfer coefficient value of hydrodynamic cavitation, conventional methods $1000 \mathrm{rpm}$ and $260 \mathrm{rpm}$ are $7.373,0.534$ and $0.121 \mathrm{l} / \mathrm{s}$ respectively.

We would like to thank Ahmad Dahlan University, Yogyakarta, Indonesia which has provided research fund and Process System Engineering Research Group, Chemical Engineering Department, Gadjah Mada University, Yogyakarta, Indonesia which has provided research facilities.

\section{References}

1. R. D. Kusumaningtyas, S. Purwono, Rocmadi, A. Budiman, IJEX, 15, 447-467. (2014)

2. T. Suganya, M. Varman, H.H. Masjuki, S. Renganathan, Renew. Sust. Energ. Rev., 55, 909941 (2016).

3. D.R. Sawitri, Sutijan, A. Budiman, JEAS, 11, 9951-9957 (2016)

4. Sunarno, Rochmadi, P. Mulyono, A. Budiman. AIP Con. Proc., 1737, 060008 (2016).

5. D.R.Wicakso,., Sutijan, Rochmadi, A. Budiman, yst, AIP Con. Proc., 1737, 060009 (2016)

6. M.D. Supardan, Fahrizal, R. Moulana, D. Safrida, Satriana, W.A.W. Mustapha, JESTEC, 12, 847859 (2017)

7. H. Sudibyo, Y.S. Pradana, T.T. Samudra, A. Budiman, Indarto, E.A. Suyono, Energy Procedia, 105, 270-276 (2017)

8. T.M. Mata, A. Martins, N.S. Caetano, Renew. Sust. Energ. Rev., 14, 217-232 (2010)

9. J. Singh, S. Gu, Renew. Sust. Energ. Rev., 14, 2596-2610 (2010)

10. E. Sualli, R. Sarbatly, Renew. Sust. Energ. Rev., 16, 4316- 4342 (2012)

11. I. Hariskos, C. Posten, Biotechnol. J., 9, 739-752 (2014)

12. M.A. Islam, R.J. Brown, I. O'Hara, M. Kent, K Heimann, Energy Convers. Manage., 88, 307-316 (2014)

13. Y.S. Pradana, H. Sudibyo, E.A. Suyono, Indarto, A. Budiman, Energy Procedia, 105, 277-282 (2017)

14. R. Halim, M.K. Danquah, P.A. Webley, Biotechnol. Adv., 30 (3), 709-732 (2012)

15. A.R. Byreddy, A. Gupta, C.J. Barrow, M. Puri, Marine Drugs, 13, 5111-5127 (2015)

16. J.Y. Lee, C. Yoo, S.Y. Jun, C.Y. Ahn, H.M. Oh, Bioresour. Technol., 101, s75-s77 (2010)

17. A.K. Lee, D.M. Lewis, P.J. Ashman, Bioresour. Technol., 128, 199-206 (2013)

18. A.K. Lee, D.M. Lewis, P.J. Ashman, J. Appl. Phycol., 27, 1881-1889 (2014)

19. I. Lee, J.I. Han, Bioresour. Technol., 186, 246-251 (2015)

20. M.D. Kostic, N.M. Jokovic, O.S. Stamenkovic, K.M. Rajkovic, P.S. Milic, V.B. Veljkovic, Ind. Crops. Prod., 52, 679- 686 (2014)

21. H. Topallar, U. Geçgel, U., Turk. J. Chem., 24, $247-253(2000)$ 